\title{
Um Encontro Inesperado: Os Pais e Seu Filho com Deficiência Mental
}

The Unexpected Meeting: The Parents and the Mentally Deficient Child

Fernando Antônio de Barros Góes

Universidade Federal de Pernambuco

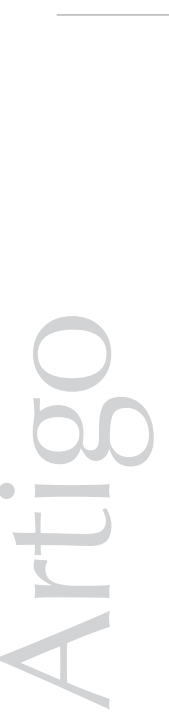




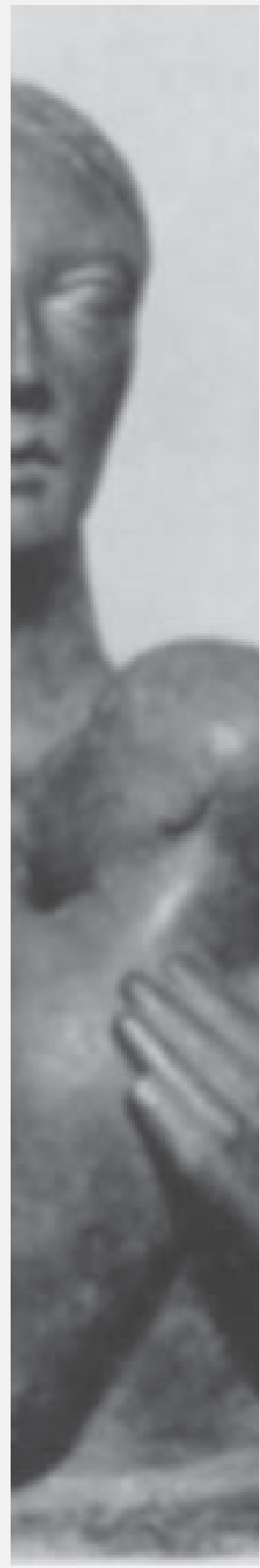

Resumo: Este artigo tem por objetivo fazer considerações sobre o nascimento de uma criança com necessidades especiais e sobre os conflitos que emergem nos pais (e seus desdobramentos) decorrentes da constatação de que o filho não nasceu saudável. Esses conflitos surgem em razão da confrontação dialética da ilusão de um filho idealizado, no qual os pais projetaram o próprio ego ideal, com a desilusão do nascimento de um filho psiquicamente deficiente, com necessidades especiais. Essas questões são o foco das análises neste trabalho, as quais foram amplamente discutidas na dissertação de mestrado do autor (ver referências), cuja fundamentação teórica tem por base a teoria psicanalítica, notadamente o campo teórico freudiano. Num primeiro momento, serão feitas análises sobre as representações psíquicas, nos pais, acerca do nascimento de um filho considerado saudável e, posteriormente, essas análises serão ampliadas, levando em consideração as construções e desconstruções dessas representações psíquicas nos pais em casos de filhos com necessidades especiais/deficiência mental, particularmente nos primeiros momentos após o nascimento.

Palavras-chave: representação psíquica (psicanálise), funcionamento parental (psicanálise), pais e filho-relacionamento, deficiência mental, família, educação especial.

Abstract:The objective of this article is to reflect about the birth of a child who has special needs and about the parents' conflicts (as will as the conflicts' extensions) that follow the confirmation that the child isn't healthy. Such conflicts emerge due to the dialectic confrontation of the idealized child illusion, in which the parents projected their own ideal ego, with the desillusion they feel by the birth of a mentally deficient child who has special needs. These issues are the focus of this paper analyses, that were thoroughly discussed in the author's Master Degue paper (as in the Bibliography), in which the theoretical base is psychoanalysis, mainly the freudian field. First the analyses on the parents psychic representations about the child's birth will be made, and these analysis will be then enlarged, taking into consideration these psychic constructions and deconstructions for the parent who have mentally deficient children, mainly in the first moments after birth.

Key words: psychic representations
"Ao filho:

Não sou eu que te gerei.

São os mortos. São meus pais, seu pai e seus ancestrais. Sinto sua multidão, somos nós e, entre nós, tu e teus descendentes filhos que hás de gerar.

Os derradeirose os do vermelho

Adão. Sou estes outros também.

A eternidade está nas coisas do tempo que são formas pressurosas.

Jorge Luiz Borges: "Al hijo", 1977. 
Ao fazer uma reflexão mais abrangente sobre o que representa

para os pais o nascimento de um filho, é possível responder, inicialmente, que há uma inquietação humana decorrente da dificuldade ou impossibilidade de compreender a origem da vida bem como de aceitar a finitude ou a morte.
O processo de espera durante a gestação e a conseqüente preparação do casal para o nascimento de um filho estabelecem, desde logo, a existência idealizada desse filho, o qual é desejado que nasça saudável, sem deficiências. Por conseguinte, a constatação da deficiência mental na criança representa, para os pais, a perda do filho até então idealizado.

A confirmação de que a criança é portadora de deficiência mental se apresenta como um transtorno psicológico importante para a família, pois torna-se uma fonte poderosa de constantes conflitos, que repercutem, profundamente, não apenas nos pais e nos demais membros do grupo familiar, mas também, de forma muito significativa, na própria criança, dada a relativa restrição de sua capacidade de elaboração das situações de ordem psicológica, cognitiva e afetiva ao longo de sua vida.

Durante todo o percurso de convívio com a pessoa portadora de necessidades especiais, ocorrem várias situações através das quais os pais estarão submetidos a freqüentes movimentos de rejeição e aceitação, de forma inconsciente, em relação ao filho, em função da possibilidade (ou não) de elaborarem psiquicamente o fato de que ele não é plenamente saudável.

Nessa complexa situação de comportamentos inconscientes e afetos ambivalentes, a aceitação desse filho "diferente", através da construção de outras representações psíquicas que contemplem a nova realidade, pode proporcionar um "novo nascer", um verdadeiro encontro entre pais e filho.

Para que esse encontro se viabilize de forma profunda, é necessário que os pais elaborem e superem o enorme estado de estranheza causado pelo filho que nasceu, em função deste ser muito diferente do filho que foi, até então, idealizado, salientando que esta idealização ocorre em função do próprio narcisismo de cada um dos pais.

Assim, torna-se necessário que eles construam novas idealizações, levando agora, em consideração, um novo ideal para esse filho que se constituiu na realidade, ou seja, todo o projeto anterior dos pais terá que ser refeito ou re-significado para que, em conseqüência, possam ofertar novos significantes ao filho que nasceu com "falhas", podendo continuar proporcionando-lhe e dirigindo-lhe investimentos libidinais.

Este artigo tem como objetivo fazer algumas considerações sobre as representações psíquicas dos pais em relação ao nascimento de um filho e, posteriormente, estender essa análise, levando em conta as construções e desconstruções dessas representações psíquicas nos pais em casos de filhos portadores de necessidades especiais. Para tanto, serão focalizados, particularmente, os primeiros momentos depois do nascimento, logo após a constatação, pelos pais, de que o filho é portador de necessidades especiais, com deficiência mental.

\section{O que representa, para os pais, o nascimento de um filho?}

"Uma ilusão não é a mesma coisa que um erro; tampouco é necessariamente um erro. [...]

O que é característico das ilusões é o fato de derivarem de desejos humanos."

Sigmund Freud, em:

O Futuro de uma Ilusão (1927).

Ao fazer uma reflexão mais abrangente sobre o que representa para os pais o nascimento 
de um filho, é possível responder, inicialmente, que há uma inquietação humana decorrente da dificuldade ou impossibilidade de compreender a origem da vida bem como de aceitar a finitude ou a morte.

Tal inquietação pode ser elaborada, dentre outras formas, pela grande maioria das pessoas, através do evento do nascimento ou, especificamente, através do nascimento de um filho, sendo este considerado pelos pais não apenas como aquele que proporcionará a imortalidade do seu Ego (negando, assim, a finitude), como também aquele que concretizará os sonhos que eles não conseguiram realizar.

O período de gestação e de espera para o nascimento de um filho, normalmente, é vivenciado pelos pais com bastante expectativa, quando, então, a criança passa a ser intensamente idealizada e provoca, desde logo, nos pais, grande investimento libidinal, evocando desejos, sonhos e um (re)encontro de sua própria história nesse filho.

Em situação de normalidade da estrutura psíquica, a mãe, durante a gravidez, já atribui ao filho 'um corpo imaginado' diferente da 'realidade do feto'. Esse 'corpo imaginado' torna-se objeto de investimentos afetivos, sendo importante destacar, sobre essa questão, que é a partir desse primeiro significante - "o corpo imaginado do filho"que se constitui a dimensão imaginária, isto é, que se constitui tudo aquilo que pertence à ordem da representação do objeto enquanto objeto do desejo e suporte da palavra.

Após o nascimento, os pais (salvo exceções) estabelecem, com a criança, um vínculo libidinal, constituído por contatos físicos, palavras, olhares, gestos carinhosos, planos para o futuro, desejos a serem realizados. Enfim, passa a existir uma ligação, um projeto com e pelo filho, ao qual a perfeição é atribuída de forma supervalorizada.

A explicação sobre quais as razões que levam os pais a produzirem essas demandas para com os filhos são fornecidas por Freud (1914) em "Sobre o Narcisismo: uma Introdução", no qual considera que a atitude afetuosa dos pais para com os filhos é uma revivescência e reprodução do próprio narcisismo, que há muito abandonaram. Esse autor destaca que os pais atribuem ao filho todas as perfeições possíveis e ocultam ou esquecem todas as suas deficiências, salientando que a doença, a morte, a renúncia ao prazer, e quaisquer restrições à sua própria vontade não o atingirão. Todas as leis da natureza e da sociedade serão ab-rogadas a seu favor. $\mathrm{O}$ filho concretizará os sonhos dourados que os pais jamais realizaram.

Como foi exposto acima, o amor dos pais pelo bebê, originariamente, é o 'renascimento' do seu próprio narcisismo [amor de si mesmo], projetado e transformado em amor objetal pelo filho, no qual se (re)conhece, se identifica, introjetando esse objeto libidinal [o filho] no Ego. Quanto a esse processo de identificação, vale salientar que, para a psicanálise, a identificação é conhecida como a mais remota expressão de um laço emocional com outra pessoa. Primeiro, constitui a forma original de laço emocional com um objeto e segundo, se torna sucedâneo para uma vinculação de objeto libidinal por meio de introjeção do objeto no Ego.

Além do que foi citado anteriormente, o pai e/ou a mãe, ao estabelecerem a escolha do filho como objeto de amor, também colocam nele o que gostariam de ser, ou seja, projetam o seu ideal do ego no filho, com o qual se 
identificam, fazendo deste seu próprio ideal. Aqui, a referência ao ideal do ego está contextualizada no relacionamento narcísico dos pais com o filho. O que o sujeito projeta diante de si como seu ideal é o substituto do narcisismo perdido da infância, na qual ele era seu próprio ideal, acrescentando que, além do aspecto individual, esse ideal tem seu aspecto social, pois constitui também o ideal de uma família, de uma classe, de uma nação.

Dessa forma, assinala-se que os 'aspectos culturais' do ideal do ego projetado no filho, no qual, por sua vez, esse filho, quando adulto, projetará o seu ideal do ego no próprio filho, cria um mecanismo em que esse ideal está na raiz da herança cultural de uma geração para outra. O superego de uma criança se constitui segundo o modelo do superego dos pais. Os elementos nele contidos é que se tornam veículos de tradição e de todos os julgamentos de valor que se transmitem de geração a geração.

A família é um núcleo de transmissão dos valores culturais. O sujeito tem o seu projeto de identificação esboçado antes mesmo de seu nascimento, e tal projeto é constituído pela herança psíquica dos pais, que já está marcada e influenciada pela cultura e por determinações próprias de cada sujeito, estabelecendo, assim, a sua constituição subjetiva.

Até aqui, configurou-se uma análise sobre a representação dos pais acerca do nascimento do filho e as vicissitudes daí decorrentes. No contexto desses pressupostos, é importante salientar que o termo "representação" ("Vorstellung"), anteriormente mencionado, deve ser compreendido conforme conceituado na metapsicologia freudiana "(Vorstellung" [representação])" é um termo que faz parte do vocabulário clássico da filosofia alemã. Freud não altera sua acepção, mas o uso que dele faz é original).
Numa análise mais focalizada, pode-se observar que o uso original que Freud faz do termo "Vorstellung" se refere ao fato de ele transferir a ênfase dada pela Filosofia clássica a esse termo enquanto algo que representa subjetivamente um objeto para aquilo que o objeto vem a inscrever-se nos sistemas mnésicos enquanto traços investidos de um quantum afetivo. Dessa forma, faz sentido referir-se não apenas a representação consciente (representação de palavra) como também a representação inconsciente (representação de coisa).

Vale ressaltar que Freud faz uma distinção, embora com pouca clareza, entre traço mnésico e representação como investimento do traço mnésico. A teoria freudiana não concebe um traço mnésico puro, ou seja, para Freud, não há uma representação totalmente desinvestida, quer pelo sistema inconsciente, quer pelo sistema consciente.

Considerando o que foi exposto acima sobre representação ("Vorstellung"), é importante notar que, depois de ocorrer efetivamente o nascimento da criança, o filho representado no sistema psíquico do pai e/ou da mãe como 'filho idealizado' será comparado ao bebê que se constituiu na realidade.

Surge, então, uma nova configuração, obtida através do resultado de semelhanças e diferenças dessa comparação, possibilitando a constituição de uma outra representação psíquica do filho, que será inscrita na cadeia simbólica de cada um dos pais, sem transtornos ou dificuldades.

O que foi exposto acima pode ser considerado uma prova de realidade, na qual ocorrem duas funções: uma, fundamental, que consiste em diferenciar o que é simplesmente representado do que é percebido, instituindo a diferenciação entre 
o mundo interior e o mundo exterior, e outra, que consiste em comparar o objetivamente percebido com o representado, de forma a 'retificar' as eventuais deformações deste.

Cabe agora, em função dos objetivos deste artigo, considerar a situação em que, ao nascer ou após o nascimento, se constate que a criança é portadora de necessidades especiais, com deficiência mental. Como se operam as primeiras representações no sistema psíquico de cada um dos pais?

\section{Um encontro inesperado: (a constatação, pelos pais, de que o filho nasceu/se tornou portador de necessidades especiais, com deficiência mental)}

Ent. 01: "Quando eu soube, eu realmente vi o meu mundo desabar, mas como uma pessoa que sabia do problema e que realmente iria fazer o quê?!"

Ent. 03: "Eu ficava me perguntando: Por que, meu Deus? Por que eu fui escolhido prá ter essa criança? [...]eu li, na época, é que, de cada 1.000 crianças que nasciam, uma nascia Down. Aí, eu me perguntei na época, disse: "Por que eu? Entre mil, eu fui escolhido prá ter uma criança como essa? Realmente, foi um desespero total!"

O nascimento de uma criança, geralmente, é um momento de alegria, um evento público, compartilhado e celebrado com parentes e amigos. Entretanto, quando ocorre a confirmação posterior de que a criança tem necessidades especiais, tal situação causa um trauma psíquico ${ }^{2}$, originando grande inquietação e angústia nos pais e na família, tornando-se um choque frente ao inesperado, que é revestido de um caráter sinistro, ominoso.
O pai e a mãe têm dificuldade de encontrar, nessa criança, vestígios ou marcas que se ajustem às representações do que eles desejam que seja o filho, de acordo com os seus Ideais. A ruptura nascisística que se opera nos pais faz com que eles tropecem em sérias dificuldades para encontrar, nessa criança, traços que se ajustem a esse Ideal que haviam previamente estabelecido.

Ocorrem transtornos na relação narcísica dos pais com o filho, o qual é muito diferente daquele até então idealizado e desejado por eles. Os pais não conseguem se (re)conhecer nesse estranho, nesse "Unheimlich" que chegou com uma falha, não sendo possível cumprir o destino que, no desejo dos pais, Ihe foi traçado.

A palavra alemã "Unheimlich", acima mencionada, significa "estranho", algo que causa espanto. Entretanto, nem tudo que é "Unheimlich" é assustador, porém pode estar relacionado a algo familiar com que não se sabe como lidar.

Aqui a referência ao termo "Unheimlich" deve ser compreendida no mesmo sentido em que os termos "Heimlich/Unheimlich" foram citados por Freud em seu artigo denominado "O Estranho" (1919), no qual ele afirma que o estranho [Unheimlich] é aquela categoria do assustador que remete ao que é conhecido, já velho, e é, há muito, familiar [Heimlich]. Esse estranho não é nada novo ou alheio, porém algo familiar e há muito estabelecido na mente, e que somente se alienou desta através do processo de recalque. Essa referência ao recalque pode ser compreendida também como o estranho ("Unheimlich") que é algo que deveria ter permanecido oculto, mas veio à tona, ou que atingiu a consciência - (retorno do recalcado).

A utilização deste termo tem o objetivo de enfatizar a dificuldade dos pais de lidarem
"Eu ficava me perguntando: Por que, meu Deus? Por que eu fui escolhido prá ter essa criança? [...]eu li, na época, é que, de cada 1.000 crianças que nasciam, uma nascia Down. Aí, eu me perguntei na época, disse: "Por que eu? Entre mil, eu fui escolhido prá ter uma criança como essa? Realmente, foi um desespero total!"
1 Recortes de entrevistas dissertação de mestrado, Góes, 2004.

2 "Em termos econômicos, o traumatismo [psíquico] caracteriza-se por um afluxo de excitações que é excessivo em relação à tolerância do sujeito e à sua capacidade de dominar e de elaborar psiquicamente essas excitações" (Laplanche e Pontalis, 1995, p. 522). 
com a representação do filho com deficiência mental. Em que pese reconhecerem o fato de que o bebê é seu filho, têm dificuldade de aceitá-lo com a característica de deficiente mental, condição essa que foi recalcada e que retorna.

A chegada desse filho causa uma ferida narcísica no pai e na mãe, colocando em questão a história de cada um deles, trazendo transtornos nas relações intersubjetivas, que são marcadas por muita frustração e dor.

A facticidade em que surge a criança decepcionante, que não se deseja conhecer ou que não se deseja (re)conhecer, e que se tornou um objeto de difícil introjeção na cadeia simbólica dos pais, determina, para esses pais, não só a perda dos ideais como também a "morte" do filho idealizado.

A percepção do filho com deficiência mental é denegada, e esse fato ocorre como resultado de uma defesa do Ego. Pode-se considerar que o objeto (o filho) não possui o atributo 'bom', não merecendo, de início, ser integrado ao Ego, e sim, permanecer no mundo externo, sendo denegado e/ou sujeito a novas elaborações, com novas possibilidades de re-inserção egóica.

Deve ser considerado, também, que, em um momento mais agudo (trauma), existiu a possibilidade de atuação do Ego na efetivação do processo de recalque, para o Id, do objeto ominoso ("Unheimlich") - o bebê que apresenta deficiência mental.

Nessa linha de pensamento, a denegação está relacionada a um processo de recalque e deve ser compreendida como um mecanismo de defesa, conforme conceituado através do termo "Verneinung", que designa um processo pelo qual o sujeito, embora formulando um dos seus desejos, pensamentos ou sentimentos até então recalcado, continua a defender-se dele, negando que lhe pertença.

É factível que os pais, inconscientemente, venham a transformar o filho objeto ideal (a criança que possibilitará a realização de sonhos, portadora do narcisismo dos pais), num objeto mau (a criança decepcionante e com falhas, que danifica os objetos internos dos pais). $\mathrm{O}$ atributo do filho deficiente não é afirmado, mas sim, negado, por ter sido considerado mau, desejando-se que permaneça fora do Ego de cada um dos pais. Um bebê, ao nascer, confirma o pai e/ou a mãe nas suas respectivas ascendência e descendência, constituindo, assim, uma fantasia de transmissão com a dupla função de representar a posição dos pais na geração e de possibilitar que eles se defendam contra a angústia de uma ruptura na sua filiação, proporcionando-lhes, assim, sentimento de continuidade existencial e imortalidade egóica, além de corresponder aos ideais parentais.

Nesses primeiros momentos, os contatos com o filho constituído na realidade, ou seja, com aquele que possui falha constatada no real do corpo, são sofridos, como observa Arias (apud Franco Jiménez, 2000, p. 141) ao afirmar que "Entonces se realizan en un primer momento, con el niño, intercambios penosos. Su madre deprimida ve en él la corporización de un monstruo, y su proprio ser es sentido en la dimensión de lo siniestro, ya que ella lo ha engendrado".

A grande possibilidade de eclosão de depressão melancólica, nesses momentos, é muito pertinente, ressaltando que, nesses casos, o que é levado em consideração é uma perda do objeto idealizado, em que o filho desejado não foi confirmado na realidade. 


\section{A "morte" do filho idealizado}

Ent. 01: "[...] Agora digo: o pai que souber de uma notícia dessa, ele não vai jamais ter força no momento, ou vai ali ... por mais que a mãe ou o pai de alguma criança assim ... só o tempo, Fernando. ... Você não tem tempo prá morte? Prá você realmente aceitar assim; não é aceitar, mas você se sentir um pouco melhor da morte de perder seu filho do que for... pronto, a gente aceitar nossos filhos assim, realmente, é o tempo"(grifos nossos). ${ }^{3}$

Para os pais, ocorre uma quase impossibilidade de o filho, antes desejado, assemelhar-se ao filho visível da realidade, pois existe uma distância significativa entre um e outro, determinada pela deficiência constituída. Esse fato dificulta o processo de identificação e provoca uma perda do objeto idealizado, uma desilusão, com as características da perda na melancolia.

Segundo Freud, em seu texto "Luto e Melancolia" (1996, ESB, vol. XIV, p. 251), essa perda tem os seguintes aspectos: "[...] as causas excitantes se mostram diferentes [comparadas às do luto], pode-se reconhecer que existe uma perda de natureza mais ideal. O objeto talvez não tenha realmente morrido, mas tenha sido perdido enquanto objeto de amor".

Sendo assim, a perda desse filho idealizado tem a característica da perda de um ideal, ou seja, a perda de um objeto que não se constituiu efetivamente na realidade.

Os pais reconhecem que, apesar de terem ganhado um bebê, inexplicavelmente, para eles, houve a perda de algo idealizado que esse filho da realidade não pôde comportar. Por não ter sido confirmado na realidade, o filho idealizado, que contém o sujeito-bebê (narcisismo) de cada um dos pais, e que não conseguiu ser re-inscrito no filho que nasceu na realidade material, retornará ao Ego de cada um deles.

A sombra desse objeto [filho desejado] instalar-se-á no Ego e nele permanecerá como objeto que foi perdido, mantendo ativada uma 'estrutura de perda', se assim pode ser considerado.

O filho idealizado [a sombra do objeto] será uma referência ao Superego/ideal do ego de cada um dos pais, possibilitando que essa instância faça cobranças ao seu respectivo Ego pelo fato de o pai e a mãe não terem gerado um bebê sem deficiência, permanecendo sempre desejada a vinda do filho saudável. Vale ressaltar que, no plano tópico, o ideal do ego representa uma formação narcísica que nunca é abandonada, portanto, os pais permanecerão sempre com o "narcisismo ferido", demandando reparação.

É importante destacar que, concomitantemente a esse momento de desilusão ("Morte" do filho idealizado), o qual é marcado pela chegada do filho portador de necessidades especiais que é constituído na realidade objetiva, surgem, nos pais, sentimentos de estranhamento com relação a esse filho pelo fato de lhes serem ativadas as mais diversas representações sociais sobre a deficiência mental, as quais já habitavam antes as suas cadeias associativas. A esse respeito, serão feitas algumas reflexões a seguir.

\section{A influência das representações sociais nas construções e desconstruções iniciais das representações psíquicas dos pais}

Ent. 03: "Porque tudo o que a gente ouvia era é que o "Down" era molinho, tinha o pescoço molinho, ficava muito com a língua
"[...] Agora digo: o pai que souber de uma notícia dessa, ele não vai jamais ter força no momento, ou vai ali ... por mais que a mãe ou o pai de alguma criança assim ... só o tempo, Fernando. ... Você não tem tempo prá morte?
3 Recorte de entrevista dissertação de mestrado, Góes, 2004. 
prá fora, não falava praticamente nada, era todo bobalhão, bobão, e a gente não queria que acontecesse com a nossa criança [...]"

"[...] Aí, aí, me vinha na cabeça crianças paraplégicas, crianças extremamente doente mental, que fica muito... numa cama, que fica muito sentado, que... então, eu fui percebendo que não era aquilo. Então, a aceitação passou a ser maior, dos seis meses em diante, passou a ser maior. Então, eu... eu... eu fui, eu diria assim, me adaptando mais a ele... ele a mim e aí a gente foi criando um vínculo de amor, de amizade, que perdura até hoje, e eu acho que vai perdurar por muitos anos[...]."

A subjetividade humana é construída na e pela cultura, e, em conseqüência, cada um dos pais sofre influência do ambiente cultural, no qual a deficiência mental é expressa por representações sociais abrangentes e impregnadas de qualidades desfavoráveis.

Os pais, em decorrência de suas próprias experiências de vida, acumulam conceitos/ crenças/valores geralmente negativos a respeito da deficiência mental, os quais compõem representações sociais que circulam no seu ambiente cultural. Essas representações sociais constituem-se em referências iniciais para construções de suas representações psíquicas ligadas ao filho que nasceu com falhas. Por isso, desvelar o discurso dos pais sobre o filho portador de necessidades especiais é compreendê-lo num contexto mais específico de sua realidade, pois é o contexto que determinará os múltiplos significados de um discurso, o que pode ser referido ao que assinala Pêcheux (1971, p.102): "as palavras mudam de sentido segundo as posições assumidas por aqueles que as empregam".
Nesse contexto, as representações sociais da deficiência mental são influenciadas pelos padrões de nossa sociedade capitalista contemporânea, que valoriza a capacidade de autonomia dos indivíduos refletida nos ideais máximos a serem alcançados, tais como capacidade de produzir, consumir e acumular riquezas.

Para obter sucesso social, pressupõe-se capacidade de alto grau de competitividade, requisito que é imposto a todos para atingir meta estabelecida como ideal, que é a de ser o número um, o primeiro ou o melhor, de acordo com os padrões nas denominadas "sociedades do espetáculo" (Debord, G., 1990).

Acreditamos que, nos modos de subjetivação capitalista, que ainda sofrem influências do racionalismo de Descartes (1596/1650) "Penso, logo existo"- ter déficit intelectual implica não poder pensar e, em conseqüência, não poder existir. A razão e a desrazão são consideradas excludentes e sem comunicação. A deficiência mental passa a ser o não-pensar, o não-existir ou o não-ser, condições essas que impedem o indivíduo portador de necessidades especiais de competir, produzir, consumir e de acumular riquezas, ou seja, está fora do circuito de troca.

Nessa perspectiva de análise, podemos nos valer das contribuições do sociólogo Tarlei (1993) a respeito da teoria das trocas. Para ele, esta se configura como a teoria mais sistemática, mais universal, sendo considerada a mais desenvolvida da Antropologia, e afirma que "[...] quem está fora do circuito de troca é considerado louco [...]", acrescentando, ainda, o que se segue: De alguma forma, todos têm que passar por uma sociedade de linguagem [...]. O que é uma sociedade de linguagem? Ela é formada por um código, que estabelece as formas e modalidades de dar e receber, de devolver, dissertação de mestrado,

Góes, 2004. 
acumular por uma rede de trocas. As trocas podem ser de três níveis: palavras, objetos, mulheres. Essa é a teoria da troca na Antropologia. O casamento é realmente dar aquilo que me é proibido usar, que é a filha, a mãe, a prima-irmã, não importa, e receber, em troca, a contrapartida. Essa pode ser uma análise interessante, porque o louco seria aquele que está incapacitado de participar do mínimo circuito de troca, de uma forma socialmente, culturalmente previsível. [...] (Tarlei, 1993, p.86).

Dentro desse contexto, pode-se considerar que as representações sociais da deficiência mental, oriundas do ambiente cultural, devem estar, geralmente, associadas à loucura e/ou doença mental.

As representações sociais caracterizam-se, segundo Vala (1996, p.151), por serem "[...] organizações de crenças, atitudes e explicações [...] que são produzidas no quadro das comunicações cotidianas suscitadas pelas identidades sociais".

A deficiência mental, sob o olhar da razão, liga-se a um sistema classificatório de operações médicas relacionadas aos sintomas e às causas. Portanto, torna-se oportuno assinalar que "a doença só tem realidade e valor de doença no interior de uma cultura que a reconhece como tal" (Foucault, 1975, p. 71).

Os pais, ao se depararem com o nascimento do filho "especial", ficarão, também, e desde logo, submetidos a um sentimento de estranhamento causado pelas mais variadas representações sociais sobre a deficiência mental, que, a priori, circulam no ambiente cultural e que, como foi dito anteriormente, são impregnadas de qualidades negativas. A partir dessa perspectiva psicossocial na qual de uma forma geral, a deficiência mental se identifica com a loucura/doença mental, é que surgem, para os pais, as primeiras representações psíquicas do filho, e que, com o passar do tempo, com o contato direto com ele na realidade material, certamente serão reconstruídas e re-significadas.

A representação social da deficiência mental traz influências à constituição da representação psíquica de cada um dos pais acerca do filho portador de necessidades especiais, com deficiência mental. Portanto, torna-se relevante assinalar, conforme já exposto, que falar sobre representação social da deficiência mental não é a mesma coisa que falar sobre representações psíquicas do pai e/ou da mãe em relação ao filho portador de necessidades especiais, com deficiência mental, em que estas últimas se revestem de um caráter singular, de acordo com a experiência individual e a constituição subjetiva de cada pai e/ou mãe a que se venham referir.

Levando agora em consideração as concepções sobre O Ideal do Ego, conforme já tratado, sabe-se que essa instância, também, forma-se a partir do que é posto social/culturalmente, e que constitui fator de transmissão cultural. Dessa forma, é oportuno perguntar: - Como, para os pais, cabe aceitar algo que se aprendeu a desvalorizar culturalmente?

Acrescentando a essa questão os outros aspectos já discutidos sobre as dificuldades de identificação e introjeção, nos pais, do filho que nasceu com falhas, pode-se agora dimensionar o quanto, para os pais, é importante elaborar novas representações psíquicas do filho que contemplem essa outra realidade, reconstruindo um novo projeto para a criança que nasceu. 


\section{Considerações finais}

Este estudo possibilitou não só analisar as construções e descontruções das representações psíquicas dos pais sobre o filho como também ofereceu uma compreensão do conflito decorrente da constatação, pelos pais, de que o filho é portador de necessidades especiais, com deficiência mental.

Esse conflito, que os coloca num impasse, terá como maior desafio ultrapassar o vazio que os separa do filho por terem dificuldade de encontrar, nele, traços que sejam seus, reconhecendo-o como um sujeito capaz de se constituir como herdeiro e depositário de seus desejos e de suas histórias.

O trauma causado pelo nascimento da criança decepcionante constitui-se, originariamente, pela restrição ao desejo de plenitude narcísica e imortalidade egóica dos pais. Esse fato estabelece uma espécie de âncora no tempo, impedindo o acontecimento de novos momentos de realizações junto ao filho com falhas que se constituiu na realidade objetiva. Enquanto não houver a renúncia, de forma significativa, desse filho idealizado, ou enquanto não for minimizado o desejo de sua confirmação na realidade objetiva, um porvir não surgirá plenamente, e, assim, ocorrerão dificuldades de uma abertura egóica para acolhimento, na cadeia simbólica dos pais, das novas representações psíquicas do filho com falhas, para o qual será necessário que ocorram novas idealizações, novos projetos que proporcionem uma nova realidade, fazendo com que, para além do encontro inesperado, surja o inesperado do encontro, através de novas possibilidades de relacionamento entre pais e filho. 
Fernando Antônio de Barros Góes Doutorando do Programa de Pós-graduação em Psicologia Cognitiva da Universidade Federal de PE-UFPE. Mestre em Psicologia Clínica pela Universidade Católica de PE-UNICAP; Pós-graduado em Psicologia Social e da Personalidade-FAFIRE/Recife-PE; professor nos Cursos de Pós-graduação de Educação Especial e de Psicopedagogia da FAFIRE/Recife-PE.

(81) 8836.8696-Recife/PE

E-mail: fernandoagoes@gmail.com / fernandoabgoes@hotmail.com

Recebido 25/05/04 Reformulado 26/04/06 Aprovado 23/06/06

AULAGNIER, Piera. A Violência da Interpretação: do Pictograma ao Enunciado. Rio de Janeiro: Imago, 1979.

BORGES, J. L. Obra Poética, "Al hijo". Buenos Aires: Emece, 1977.

FOUCAULT, Michel. Doença Mental e Psicologia. Rio de Janeiro: Tempo Brasileiro, 1975.

FRANCO JIMÉNEZ. El Niño con Síndrome de Down y sus Padres. In: Plá \& Carrizosa. Sujeto, Inclusión y Diferencia. México: Universidad Autónoma Metropolitana-Xochimilco, 2000. p. 141.

FREUD, S. Sobre o Narcisismo: uma Introdução. In: __ _ . Edição Standard Brasileira das Obras Completas. Rio de Janeiro: Imago, 1914-1996, v. XIV.

Luto e Melancolia. In: Edição Standard Brasileira das Obras Completas. Rio de Janeiro: Imago, 1914-1996, v. XIV.

FREUD, S. Psicologia do Grupo e Análise do Ego. In: Edição Standard Brasileira das Obras Completas. Rio de Janeiro: Imago, 1921-1996, v. XVIII.

O Ego e o ld. In: Edição Standard Brasileira das Obras Completas. Rio de Janeiro: Imago, 1923-1996, v. XIX

O Futuro de uma Ilusão. In: Edição Standard Brasileira das Obras Completas. Rio de Janeiro: Imago, 1927-1996, v. XXI.

Novas Conferências Introdutórias da Psicanálise. In: Edição Standard Brasileira das Obras Completas. Rio de Janeiro: Imago, 1933-1996, v. XXII.
GÓES, Fernando Barros. Os Pais e seu Filho Portador de Necessidades Especiais/Deficiência Mental: um Encontro Inesperado. Dissertação de Mestrado, Recife: Universidade Católica de Pernambuco - UNICAP, 2004.

GÓES. F. A. B. Um Encontro Inesperado: uma Abordagem Psicanalítica. Recife: Imprensa Universitária - UFRPE, 2005.

LAPLANCHE, J. Vocabulário de Psicanálise: Laplanche e Pontalis São Paulo: Martins Fontes, 1995.

NICOLAÏDIS, N. A Representação-Ensaio Psicanalítico. São Paulo: Escuta, 1989.

PÊCHEUX, M. Analyse du Discours. Paris: Dunot, 1971. ROCHA, Zeferino. Narcisismo: Abordagem Freudiana. In: Relatório Oficial do IV Congresso do Círculo Psicanalítico da Bahia, 1981. Texto mimeografado.

ROUDINESCO \& PLON. Dicionário de Psicanálise. Rio de Janeiro: Jorge Zahar, 1998.

SINASON, Valerie. Compreendendo seu Filho Deficiente. In: Clínica Tavistock-Série Elsie Osborne. Rio de Janeiro: Imago, 1993.

TARLEI, Luiz. Relativizando a Loucura. Revista Boletim, no 9, p.86. Associação Psicanalítica de Porto Alegre, 1993.

VALA, J. As Representações Sociais no Quadro dos Paradigmas e Metáforas da Psicologia Social. João Pessoa: UFPB, 1996. 